\title{
Consumo de nutrientes e comportamento ingestivo de cordeiros da raça Santa Inês alimentados com rações com diferentes níveis de energia metabolizável
}

\author{
Rildson Melo Fontenele ${ }^{1}$, Elzânia Sales Pereira ${ }^{2}$, Maria Socorro de Souza Carneiroํ, Patrícia \\ Guimarães Pimentel ${ }^{3}$, Magno José Duarte Cândido², José Gilson Louzada Regadas Filho ${ }^{4}$ \\ 1 Universidade Federal do Ceará, Centro de Ciências Agrárias, Departamento de Zootecnia. \\ 2 Universidade Federal do Ceará, Centro de Ciências Agrárias, Departamento de Zootecnia. Bolsista de produtividade - CNPq \\ ${ }^{3}$ Universidade Federal do Ceará, Centro de Ciências Agrárias, Departamento de Zootecnia. Bolsista PRODOC-CAPES. \\ ${ }^{4}$ Universidade Federal de Viçosa, Departamento de Zootecnia.
}

RESUMO - Objetivou-se avaliar o consumo de nutrientes e o comportamento ingestivo de cordeiros da raça Santa Inês na fase de cria alimentados com diferentes níveis de energia metabolizável (EM). Foram utilizados 20 cordeiros não-castrados, com idade e peso corporal médio de 50 dias e 13,00 \pm 0,56 kg, respectivamente, distribuídos em quatro tratamentos experimentais com diferentes níveis de energia metabolizável (2,08; 2,28; 2,47 e 2,69 Mcal de EM/kg de matéria seca), em delineamento em blocos casualizados, com cinco repetições. Como volumoso utilizou-se feno de capim-tifton adicionado à ração concentrada. Os níveis de energia metabolizável (EM) tiveram efeito linear sobre os consumos de matéria seca, matéria orgânica, proteína bruta, extrato etéreo, carboidratos não-fibrosos e nutrientes digestíveis totais, expressos em g/dia. O consumo de FDN, expresso em \%PV e kg/PV ${ }^{0,75}$, decresceu linearmente com o aumento dos níveis de energia nas rações, devido à redução no teor de FDN na matéria seca total das rações. Os tempos de alimentação e mastigação total, expressos em hora/dia, diminuíram linearmente com os níveis energéticos das rações experimentais. Em compensação, o tempo de ócio aumentou linearmente e o de ruminação não foi influenciado pelos níveis energéticos das rações. O número de bolos ruminais, de mastigações merícicas e de mastigações merícicas por bolo ruminal e o tempo de mastigações merícicas por bolo ruminal não foram influenciados pelos níveis de energia metabolizável nas rações. O aumento dos níveis de energia metabolizável das rações influencia o consumo de nutrientes e o comportamento ingestivo de cordeiros da raça Santa Inês na fase de cria.

Palavras-chave: ingestão, ócio, relação volumoso:concentrado, ruminação

\section{Nutrient intake and ingestive behavior of Santa Inês lambs fed diets with different levels of metabolizable energy}

\begin{abstract}
The objective of this work was to evaluate the nutrient intake and ingestive behavior of growing Santa Inês lambs fed different levels of metabolizable energy (ME). It was used 20 non-castrated lambs at 50 days of age and with $13.00 \pm 0.56 \mathrm{~kg}$ of body weight. The animals were distributed into four experimental treatments with different levels of metabolizable energy $(2.08,2.28,2.47$ and $2.69 \mathrm{Mcal} / \mathrm{kg}$ of dry matter) in a randomized block design with five replications. It was used as roughage tifton hay added to concentrate diet. Levels of metabolizable energy (ME) linearly affected intakes of dry matter, organic matter, crude protein, ether extract, no-fiber carbohydrates, and total digestible nutrients, expressed in $\mathrm{g} / \mathrm{day}$. The NDF intake, expressed as $\% \mathrm{BW}$ and $\mathrm{kg} / \mathrm{BW}^{0.75}$, decreased linearly with the increase of levels of energy in the diet due to the reduction in NDF content in the total dietary dry matter. Feeding and total chewing time, expressed in hour/day, decreased linearly with the energy levels of the experimental diets. However, idle time increased linearly, whereas rumination was not influenced by energy levels of the diets. Number of ruminate boli, of ruminating chews, of ruminating chews per bolus and time of chewing per bolus were not influenced by levels of metabolizable energy in the diets. Increase in metabolizable energy levels of diets affects intake of nutrients and ingestive behavior of growing Santa Inês lambs.
\end{abstract}

Key Words: idle, intake, roughage:concentrate ratio, rumination

\section{Introdução}

O consumo voluntário pode ser definido como sendo a quantidade de alimento ingerido espontaneamente por um animal ou grupo de animais em determinado período, com livre acesso ao alimento, um dos principais fatores limitantes da produção de ruminantes (Van Soest, 1994). O consumo de matéria seca é essencial para o desempenho animal por 
determinar a ingestão de nutrientes, considerando como principais a proteína e a energia, necessários para o atendimento das exigências de mantença e produção.

No entanto, para compreender o consumo diário de alimento, é necessário estudar seus componentes individualmente, que podem ser descritos pela quantidade de alimento fornecido e consumido por dia, pela duração média do tempo para consumir e pela velocidade de alimentação de todos os alimentos fornecidos. Cada um desses processos é o resultado da interação entre o metabolismo do animal e das propriedades físicas e químicas da dieta, estimulando receptores da saciedade. Dessa forma, mensurar o comportamento de alimentação e ruminação animal pode proporcionar mecanismo de auxílio para análise desses componentes (Miranda et al., 1999).

Existem vários fatores envolvidos no controle da ingestão de alimentos, e podem ser divididos em três mecanismos: fisiológico, onde o controle é feito pelo balanço nutricional relacionado à manutenção do equilíbrio energético; o físico, associado à capacidade de distenção do rúmen e do teor de fibra da ração; e o psicogênico, que envolve a resposta do animal a fatores inibidores ou estimuladores, relacionados ao alimento e ao ambiente (Mertens, 1994).

O comportamento ingestivo tem sido estudado com relação às características dos alimentos, à motilidade do rúmen-retículo, ao estudo da vigília e ao ambiente. Esses estudos servem como avaliação das dietas e possibilitam ajustar o manejo alimentar de diferentes categorias, para obtenção do melhor desempenho produtivo (Mendonça et al., 2004).

Desta forma, objetivou-se com este estudo avaliar o efeito de níveis energéticos das rações fornecidas sobre os consumos de nutrientes e o comportamento ingestivo de cordeiros da raça Santa Inês na fase de crescimento.

\section{Material e Métodos}

O experimento foi desenvolvido no Setor de Ovinocaprinocultura do Departamento de Zootecnia da Universidade Federal do Ceará, em Fortaleza, Ceará. O município de Fortaleza situa-se na zona litorânea, a 15,49 m de altitude, $30^{\circ} 43^{\prime} 02^{\prime \prime}$ de latitude sul e $38^{\circ} 32^{\prime} 35^{\prime \prime}$ de longitude oeste. A precipitação média anual é de $1.378,3 \mathrm{~mm}$ e a umidade relativa do ar, de $77 \%$.

Foram utilizados 20 cordeiros da raça Santa Inês, nãocastrados, com peso corporal (PC) inicial de 13,0 kg $\pm 0,56 \mathrm{~kg}$ e aproximadamente 50 dias de idade. Os animais foram confinados em baias individuais com piso de concreto e providas de comedouro e bebedouro. Inicialmente, os animais foram pesados, identificados e submetidos ao programa de controle sanitário de ecto e endoparasitas, posteriormente distribuídos em quatro tratamentos experimentais com diferentes níveis de energia metabolizável (2,08; 2,28; 2,47 e 2,69 Mcal de EM/kg de MS), em delineamento em blocos casualizados, com cinco repetições. Como volumoso utilizou-se feno de capim-tifton 85 adicionado à ração concentrada. As rações experimentais foram formuladas conforme o NRC (1985) e fornecidas à vontade, uma vez ao dia, às $7 \mathrm{~h}$, e ajustadas de forma a permitir sobras em torno de $20 \%$ do fornecido, com água permanentemente à disposição dos animais. A quantidade de ração oferecida foi registrada diariamentee, semanalmente, foram coletadas amostras dos concentrados, do feno e das sobras por animal para mensuração do consumo de nutrientes. Ao final do período experimental, formaram amostra composta/tratamento/animal. Posteriormente, foram présecadas em estufa ventilada a $55^{\circ} \mathrm{C}$ e processadas em moinho tipo Willey com peneira de malha de $1 \mathrm{~mm}$, para posteriores análises laboratoriais.

Os ingredientes, os concentrados, o feno (Tabela 1) e as sobras foram submetidos às análises de matéria seca, matéria mineral, proteína bruta e extrato etéreo, conforme os procedimentos recomendados pela AOAC (1990). As análises de fibra em detergente neutro (FDN) e ácido (FDA), nitrogênio insolúvel em detergente neutro (NIDN), nitrogênio insolúvel em detergente ácido (NIDA) foram realizadas segundo Van Soest et al. (1991) e lignina (ácido sulfúrico 72\%) foi obtido pelo método sequencial de Van Soest \& Robertson (1980). Os teores de carboidratos totais foram obtidos conforme Sniffen et al. (1992) e os carboidratos não fibrosos (CNF) segundo a equação proposta por Weiss (1999): \%CT $=100-(\% \mathrm{~PB}+\% \mathrm{EE}+\%$ Cinzas $)$ e $\% \mathrm{CNF}=100$ -(\%FDNcp + \%PB + \%EE + \%cinzas). Para os concentrados, devido à presença de ureia em sua constituição, o teor de CNF foi calculado conforme proposto por Hall (2000), sendo $\mathrm{CNF}=100-[(\% \mathrm{~PB}-\% \mathrm{~PB}$ derivado da ureia $+\%$ da ureia $)$ $+\%$ FDNcp + \%EE + \%cinzas ].

Para estimativa do consumo de NDT, utilizou-se o consumo de matéria seca pelos animais do experimento de desempenho, multiplicado pelo percentual de NDT das rações obtido no experimento de digestibilidade.

Para mensuração do comportamento ingestivo, os animais foram submetidos à observação visual entre o $100^{\circ}$ e o $101^{\circ}$ dia experimental. No primeiro dia de observação, os animais foram avaliados durante três períodos de duas horas (8 às 10 h; 14 às 16 h e 18 às 20 h), cujas informações foram compiladas para se estimar o número de mastigações merícicas por bolo ruminal e o tempo despendido com mastigação merícica por bolo ruminal, utilizando-se 
Tabela 1 - Composição bromatológica dos ingredientes da ração em \% MS

\begin{tabular}{|c|c|c|c|c|c|c|c|}
\hline Nutrientes & Feno & Milho & Soja & Conc. 1 & Conc. 2 & Conc. 3 & Conc. 4 \\
\hline Matéria seca & 92,73 & 91,44 & 92,54 & 90,30 & 90,18 & 90,94 & 90,30 \\
\hline Matéria mineral & 6,03 & 1,74 & 6,84 & 3,53 & 3,76 & 3,56 & 3,71 \\
\hline Proteína bruta & 9,94 & 9,39 & 44,05 & 21,14 & 21,72 & 22,00 & 22,27 \\
\hline Extrato etéreo & 0,84 & 5,36 & 4,13 & 3,60 & 4,30 & 5,00 & 4,26 \\
\hline Fibra em detergente neutro & 75,03 & 14,78 & 15,78 & 15,91 & 15,15 & 16,01 & 14,87 \\
\hline Fibra em detergente ácido & 36,32 & 4,78 & 9,24 & 5,63 & 5,67 & 2,70 & 5,83 \\
\hline $\mathrm{FDN}_{\mathrm{CP}}$ & 67,91 & 12,76 & 13,74 & 14,16 & 13,72 & 14,61 & 13,45 \\
\hline Carboidratos totais & 83,19 & 83,51 & 44,98 & 71,73 & 70,23 & 69,43 & 69,75 \\
\hline Carboidratos não-fibrosos & 15,28 & 70,75 & 31,24 & 59,16 & 58,64 & 57,03 & 58,56 \\
\hline
\end{tabular}

Tabela 2 - Composição percentual e bromatológica das rações experimentais

\begin{tabular}{|c|c|c|c|c|}
\hline \multirow[b]{2}{*}{ Composição percentual (\%MN) } & \multicolumn{4}{|c|}{ Energia metabolizável (Mcal/kg MS) } \\
\hline & 2,08 & 2,28 & 2,47 & 2,69 \\
\hline Feno de capim-tifton & 75,00 & 62,50 & 50,00 & 37,50 \\
\hline Fubá de milho ${ }^{1}$ & 77,90 & 77,60 & 77,40 & 77,39 \\
\hline Farelo de soja ${ }^{1}$ & 20,00 & 20,00 & 20,20 & 20,00 \\
\hline Ureia $^{1}$ & 0,88 & 1,18 & 1,22 & 1,25 \\
\hline Calcário $^{1}$ & 0,00 & 0,26 & 0,31 & 0,62 \\
\hline Cloreto de sódio ${ }^{1}$ & 0,88 & 0,62 & 0,44 & 0,35 \\
\hline Premix mineral ${ }^{1,2}$ & 0,06 & 0,04 & 0,13 & 0,13 \\
\hline \multicolumn{5}{|l|}{ Composição bromatológica (\%MS) } \\
\hline Matéria seca & 92,12 & 91,77 & 91,83 & 91,21 \\
\hline Matéria mineral & 5,40 & 5,18 & 4,80 & 4,58 \\
\hline Proteína bruta & 12,74 & 14,36 & 15,97 & 17,65 \\
\hline Carboidratos totais & 80,33 & 78,33 & 76,31 & 74,79 \\
\hline Carboidratos não-fibrosos & 26,25 & 31,54 & 36,16 & 42,33 \\
\hline Nutrientes digestíveis totais & 54,33 & 62,13 & 61,50 & 74,30 \\
\hline
\end{tabular}

cronômetro digital. No segundo dia, o comportamento ingestivo foi determinado visualmente, a intervalos de cinco minutos, durante 24 horas, para determinação do tempo despendido com alimentação, ruminação e ócio (Johnson \& Combs, 1991). Na observação noturna dos animais, o ambiente foi mantido com iluminação artificial, após período de adaptação.

As variáveis referentes ao comportamento ingestivo foram obtidas pelas equações:

$\mathrm{EAL}=\mathrm{CMS} / \mathrm{TAL} ; \mathrm{EAL}=\mathrm{CMFDN} / \mathrm{TAL}$;

ERU $=$ CMS/TRU; ERU = CMFDN/TRU;

$\mathrm{TMT}=\mathrm{TAL}+\mathrm{TRU}$;

BOL = TRU/MMtb; MMnd = BOLMMnb, em que:

EAL (gMS/h, gFDN/h) = eficiência de alimentação; CMS $(\mathrm{gMS} / \mathrm{dia})=$ consumo de MS; TAL $(\mathrm{h} / \mathrm{dia})=$ tempo de alimentação; CMFDN (gFDN/dia) = consumo de FDN; ERU (gMS/h, gFDN/h) = eficiência de ruminação; TRU (h/dia) = tempo de ruminação; TMT (h/dia) = tempo de mastigação total; BOL (№ /dia) = número de bolos ruminais; MMtb (seg/bolo) = tempo de mastigação merícica por bolo ruminal; e MMnb (№/bolo) = número de mastigações merícicas por bolo ruminal (Polli et al., 1996).

As variáveis experimentais foram submetidas à análise de variância e regressão utilizando-se o Sistema de Análises Estatísticas e Genéticas - SAEG (UFV, 2007).

\section{Resultados e Discussão}

Foi detectado efeito dos níveis de energia metabolizável (EM; $\mathrm{P}<0,05$ ) sobre o consumo de matéria seca, expresso em $\mathrm{g} / \mathrm{dia}$ e $\mathrm{g} / \mathrm{kg}^{0,75}$, apresentando efeito linear crescente (Tabela 3). Contudo, para o consumo de MS, expresso em \%PV, não foi observada influência dos níveis de energia na dieta, registrando-se consumo médio de 4,41\%PV (Tabela 3). Resultados semelhantes foram obtidos por Alves et al. (2003) estudando três níveis de EM (2,42; 2,66 e 2,83 Mcal de 
Tabela 3 - Consumo de nutrientes por cordeiros da raça Santa Inês mantidos com rações com diferentes níveis de energia metabolizável

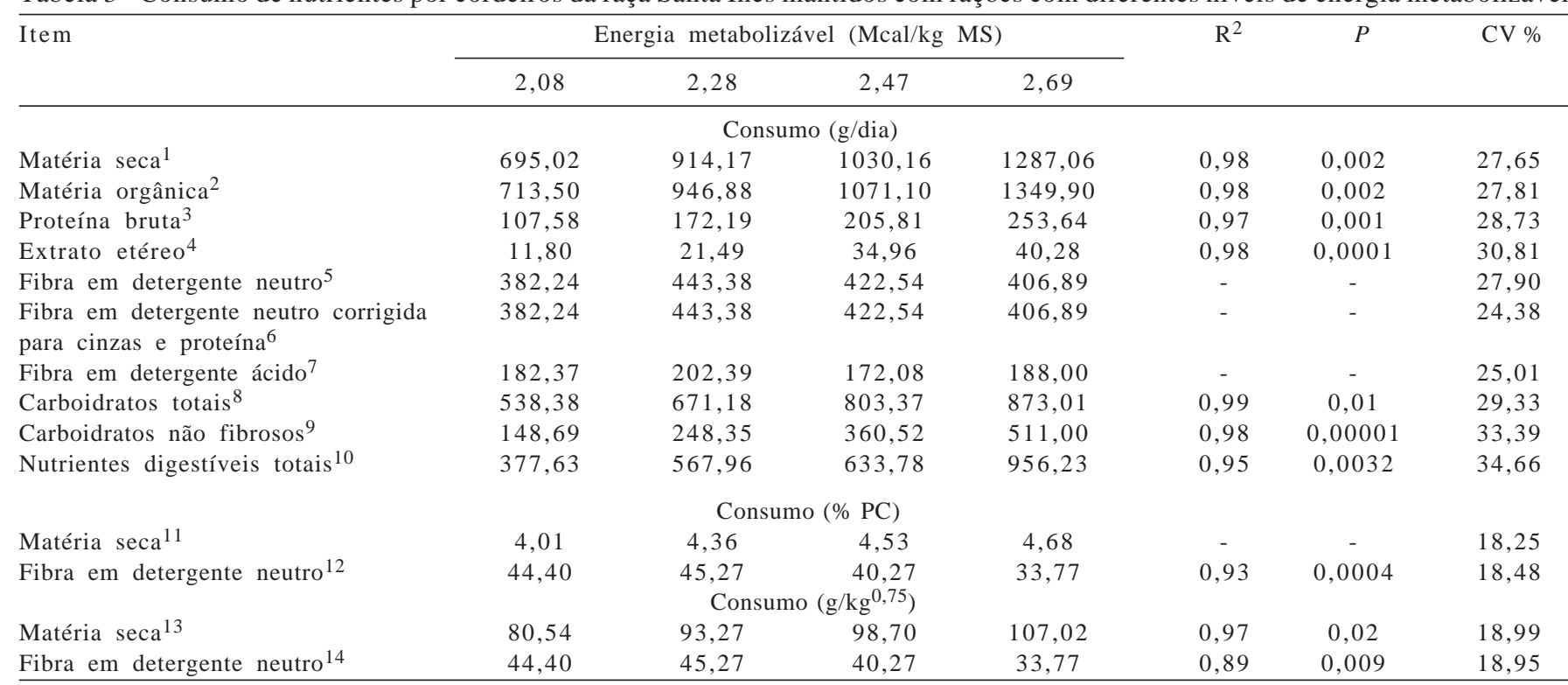

${ }^{* *}=\mathrm{P}<0,05 ; \mathrm{NS}=$ não-significativo; ${ }^{1} \mathrm{Y}=-1249,47+937,54 \mathrm{EM}^{* *} ;{ }^{2} \hat{\mathrm{Y}}=-1378,86+1008,10 \mathrm{EM}^{* *} ;{ }^{3} \hat{\mathrm{Y}}=-364,41+230,94 \mathrm{EM}^{* *} ;{ }^{4} \hat{\mathrm{Y}}=-88,13+48,45 \mathrm{EM}{ }^{* *}$ ${ }^{5} \tilde{\mathrm{Y}}=413,76^{\mathrm{NS}} ;{ }^{6} \tilde{\mathrm{Y}}=415,42^{\mathrm{NS}} ;{ }^{7} \tilde{\mathrm{Y}}=186,41^{\mathrm{NS}} ;{ }^{8} \hat{\mathrm{Y}}=-599,38+555,90 \mathrm{EM}^{* *} ;{ }^{9} \hat{\mathrm{Y}}=-1106,60+597,96 \mathrm{EM}^{* *} ; 10 \hat{\mathrm{Y}}=1503,33+898,00 \mathrm{EM}{ }^{* * *} ;{ }^{11} \tilde{\mathrm{Y}}=4,39^{\mathrm{NS}} ;{ }^{2} \hat{\mathrm{Y}}=4,91-$ $1,25 \mathrm{EM}^{* *} ;{ }^{13} \hat{\mathrm{Y}}=-3,48+41,37 \mathrm{EM}^{* *} ;{ }^{14} \hat{\mathrm{Y}}=86,44-19,07 \mathrm{EM}^{* *}$

EM/kg de MS) em ovinos Santa Inês. Mertens (1994) destacou que a base para expressar consumo não é a mesma para os mecanismos físicos e fisiológicos de controle. Para rações de baixa qualidade, em que ingestão é limitada pelo enchimento do rúmen, é ideal expressa-lo em \%PV, por se encontrar mais relacionado ao tamanho e a capacidade do trato digestório. Quando o consumo é limitado pela demanda fisiológica de energia, a melhor forma de expressá-lo é com base no peso metabólico.

O consumo de matéria orgânica, proteína bruta, extrato etéreo, carboidratos não fibrosos e nutrientes digestíves totais, expressos em g/dia, apresentaram comportamento semelhante ao consumo de MS, registrando-se efeito linear crescente $(\mathrm{P}<0,05$; Tabela 3$)$. Isso ocorreu devido aos maiores níveis destes nutrientes no concentrado (Tabela 2). Observou-se, também, aumento no consumo de carboidratos totais (Tabela 3), apesar da diminuição desse nutriente à medida que se aumentavam os níveis de energia nas rações (Tabela 2). A provável explicação para este fato se deve ao aumento na digestibilidade desse nutriente. Esse resultado corrobora com o obtido por Medeiros et al. (2007), estudando o efeito de quatro níveis de concentrado (20; 40; 60 e 80\%) em rações de ovinos da raça Morada Nova, onde observaram aumento no consumo de carboidratos totais, devido à maior digestibilidade desse nutriente nas rações.

O consumo de FDN (\%PV e kg/PV ${ }^{0,75}$ ) foi influenciado de maneira linear decrescente $(\mathrm{P}<0,05)$ com o aumento dos níveis de energia nas dietas (Tabela 3), devido à redução no teor de FDN na matéria seca total das rações (Tabela 2). De acordo com Mertens (1994), quando a densidade energética da dieta é elevada (baixa concentração de FDN), em relação às exigências do animal, o consumo pode ser limitado pela demanda energética, não ocorrendo repleção ruminal. Para dietas de densidade energética baixa (teor de FDN elevado), o consumo poderá ser limitado pelo enchimento do rúmenretículo. Os resultados permitem inferir que a ingestão de alimentos foi, possivelmente, limitada pelo enchimento do compartimento ruminal. Assim, se o consumo diário é a meta primária, teorias relacionadas à regulação do consumo a longo prazo são as mais apropriadas como ponto inicial para derivação das equações. No entanto, equações estáticas podem ser mais realísticas ao início do desenvolvimento do modelo, pois se estimará o consumo necessário à ingestão diária quando os animais estão adaptados à dieta, em um estado de equilíbrio (Mertens, 1987). É importante ressaltar que o teor ótimo de FDN na ração não deve ser fixo e deve variar conforme o requerimento de energia líquida do animal. Quando o volume da ração é o fator limitante de consumo, os animais necessitam de maior ingestão de nutrientes para suprir a demanda fisiológica; contrariamente, ao se adicionar concentrado, obtêm-se aumento da ingestão de energia até determinado ponto - ponto de transição entre o controle físico e fisiológico - em seguida, o consumo estabiliza-se. Nesse caso, o animal ingere energia suficiente para atender sua demanda fisiológica.

Os consumos diários de $\mathrm{FDN}_{\mathrm{CP}}$ e FDA não foram influenciados $(\mathrm{P}>0,05)$ pelos níveis energéticos das rações (Tabela 3), apesar de a concentração destes nutrientes ter 
diminuído com o aumento da inclusão de concentrados nas rações (Tabela 2). Esses resultados diferem dos obtidos por Alves et al. (2003), os quais observaram efeito linear decrescente para o consumo de FDA quando os animais dispunham de níveis mais altos de energia na dieta.

Neste sentido, Mertens (1987), empregando características de alimento e exigências nutricionais, baseando-se principalmente nos resultados demonstrados por Conrad et al. (1964), propôs um modelo estático para estimação do consumo em vacas em lactação, o qual apresenta natureza bifásica em que, dietas que apresentam níveis elevados de energia têm seu consumo determinado pelo atendimento das exigências do animal. Porém, dietas que apresentem baixos níveis energéticos têm como principal entrave ao consumo, à capacidade física de ingestão ou enchimento. O referido autor sugeriu ainda que quando o consumo for limitado por entraves físicos, o consumo de FDN deverá ser mantido próximo ao valor de 12,0 $\pm 1,0 \mathrm{~g} / \mathrm{kg}$ PC. Baseando-se nestas argumentações, nota-se que o efeito de repleção ruminal ocorreu durante este experimento, uma vez que nos níveis 2,08; 2,28; 2,47 e 2,69 Mcal/kg na MS registraram-se valores de 13,89; 15,75; 15,36 e 14,79 g/kg PC, respectivamente. Isto pode ser explicado pelos níveis elevados de FDN nas rações experimentais, onde foram registrados valores de 602,50; 525,70; 455,20 e 374,30 g/kg na MS.

O tempo de alimentação, expresso em hora/dia, diminuiu linearmente $(\mathrm{P}<0,05)$ com os níveis energéticos das rações experimentais (Tabela 4). Com relação ao tempo de ócio, observou-se aumento linear, no entanto, o tempo de ruminação não foi influenciado ( $\mathrm{P}>0,05)$ pelos níveis de EM (Tabela 4). Estes resultados diferiram dos obtidos por Dulphy et al. (1980), os quais relataram decréscimo no tempo despendido no processo fisiológico de ruminação com o aumento da inclusão de concentrado na dieta. Assim como Macedo et al. (2007), ao incrementarem o teor de FDN na dieta de ovinos com a substituição da silagem de sorgo por bagaço de laranja $(70,78 ; 60,23 ; 50,69$ e 43,39\% de FDN, para os níveis de adição de 0; 25; 50 e 75\% de bagaço de laranja, respectivamente). Em concordância com os referidos pesquisadores, França et al. (2009) e Mendes et al. (2010) observaram decréscimo no tempo despendido com a atividade de ruminação, ao avaliarem, respectivamente, níveis crescentes de energia metabolizável (2,2; 2,8 e 3,4 Mcal/kg MS) para ovelhas Morada Nova no terço final de gestação e diferentes fontes de FDN na dieta de ovinos Santa Inês.

Com relação à eficiência de alimentação, expressa em g MS/h e g FDN/h, e eficiência de ruminação, expressa em gramas de FDN/h, não foram registrados efeitos dos níveis energéticos sobre essas variáveis (Tabela 4). Segundo Van Soest (1994), o tempo despendido em ruminação, influenciado pela natureza da dieta, é proporcional ao teor de parede celular dos volumosos (quanto maior a participação de volumosos na dieta maior o tempo despendido em ruminação). Contudo, a eficiência de ruminação ou mastigação pode ser reduzida em dietas com maiores proporções de concentrado, fato registrado neste estudo. A redução na eficiência de ruminação não pode ser compensada pelo prolongamento da atividade de ruminação. A eficácia de ruminação é importante no controle da utilização de volumosos e pode restringir a utilização de alimentos de baixa qualidade, comprometendo a produção animal (Welch, 1982).

O tempo de mastigação total (min/dia) foi influenciado pelos níveis energéticos das rações experimentais, apresentando efeito linear decrescente. Segundo Dulphy et al. (1980), quando decrescem os constituintes da parede celular da dieta, aumentando o teor de amido, decresce o tempo de mastigação total, o que pode ser observado com a redução linear verificada nos dados obtidos neste estudo (Tabela 5).

Já o número de bolos ruminais, de mastigações merícicas e de mastigações merícicas por bolo ruminal e o tempo de mastigações merícicas por bolo ruminal não foram influenciados $(\mathrm{P}>0,05)$ pelos níveis de energia metabolizável nas rações (Tabela 5).

Tabela 4 - Comportamento ingestivo de cordeiros da raça Santa Inês submetidos a rações com diferentes níveis de energia metabolizável

\begin{tabular}{|c|c|c|c|c|c|c|c|}
\hline \multirow[t]{2}{*}{ Variáveis } & \multicolumn{4}{|c|}{ Energia metabolizável (Mcal/kg MS) } & \multirow[t]{2}{*}{$\mathrm{R}^{2}$} & \multirow[t]{2}{*}{$P$} & \multirow[t]{2}{*}{$\mathrm{CV} \%$} \\
\hline & 2,08 & 2,28 & 2,47 & 2,69 & & & \\
\hline Tempo de alimentação (h/dia) ${ }^{1}$ & 5,83 & 5,87 & 4,85 & 4,77 & 0,74 & 0,02 & 12,23 \\
\hline Eficiência de alimentação (g MS/h) ${ }^{2}$ & 485,67 & 404,33 & 304,48 & 281,43 & - & - & 27,69 \\
\hline Eficiência de alimentação (g FDN/h) $)^{3}$ & 1116,72 & 772,96 & 706,11 & 754,11 & - & - & 36,85 \\
\hline Tempo de ruminação (h/dia) ${ }^{4}$ & 9,73 & 8,77 & 8,93 & 8,32 & - & - & 13,18 \\
\hline Eficiência de ruminação (g MS/h$)^{5}$ & 978,56 & 585,84 & 522,69 & 429,11 & 0,78 & 0,007 & 29,39 \\
\hline Eficiência de ruminação (g FDN/h) ${ }^{6}$ & 1788,48 & 1208,22 & 1286,88 & 1385,23 & - & - & 39,55 \\
\hline Ócio $(\mathrm{h} / \text { dia })^{7}$ & 5,10 & 5,65 & 6,14 & 6,50 & 0,70 & 0,03 & 18,03 \\
\hline
\end{tabular}

** = P<0,05; NS = não-significativo; ${ }^{1} \hat{\mathrm{Y}}=10,35-2,10 \mathrm{EM}^{* *} ;{ }^{2} \tilde{\mathrm{Y}}=368,97^{\mathrm{NS}} ;{ }^{3} \tilde{\mathrm{Y}}=837,47^{\mathrm{NS}} ;{ }^{4} \tilde{\mathrm{Y}}=8,93^{\mathrm{NS}} ;{ }^{5} \hat{\mathrm{Y}}=2550,69-809,76 \mathrm{EM}{ }^{* *} ;{ }^{6} \tilde{\mathrm{Y}}=1417,20^{\mathrm{NS}} ;{ }^{7} \hat{\mathrm{Y}}=38,54+$ $229,62 \mathrm{EM}^{* *}$ 
A soma dos períodos 1 e 2 , referentes ao período de 6 às $12 \mathrm{~h}$ e de 12 às $18 \mathrm{~h}$, correspondeu ao maior tempo despendido com consumo (87,16\% do consumo total), logo, o consumo concentrou-se durante o dia (Figura1). Essas observações foram registradas também por Pereira et al. (2009), Dado \& Allen (1995) e Macedo et al. (2007), que obtiveram percentual de $57,12 \%$ do tempo despendido para alimentação ao somarem os períodos 1 e 2 . A ingestão dos alimentos foi maior durante o dia, correspondendo a 95,05\% da atividade de alimentação no período de 6 às 18 h. Ainda segundo Dado \& Allen (1995), o consumo de MS é maior após o fornecimento da ração, quando o alimento ainda está fresco.

De acordo com Forbes (1995), como ruminantes são animais de hábito diurno, a atividade de alimentação é mais frequente durante o dia que à noite, no entanto, este comportamento pode variar em situações de altas temperaturas, o que não ocorreu neste estudo.
A ruminação ocorreu principalmente no período noturno, horário em que comumente a temperatura do ar é mais amena. A ruminação foi realizada em grande parte entre os períodos 3 e 4, ou seja, das 18 às 24 e das 24 às 6 h, respectivamente (Figura 1). O padrão diário da atividade de ruminação apresentou valores elevados após 10 horas do fornecimento da alimentação diária, período de 18 às $24 \mathrm{~h}$, mantendo-se em plena atividade durante as 24 horas subsequentes, período de 24 às $6 \mathrm{~h}$. Polli et al. (1996) relataram que a distribuição da atividade de ruminação é bastante influenciada pela alimentação, já que a ruminação se processa logo após os períodos de alimentação, quando o animal está tranquilo. Esses resultados estão de acordo como obtidos por Macedo et al. (2007), os quais observaram percentual de $54,54 \%$ para o tempo despendido com o processo de ruminação.

Tabela 5 - Comportamento ingestivo de cordeiros da raça Santa Inês submetidos a rações com diferentes níveis de energia metabolizável

\begin{tabular}{|c|c|c|c|c|c|c|c|}
\hline \multirow[t]{2}{*}{ Variável } & \multicolumn{4}{|c|}{ Energia metabolizável (Mcal/kg MS) } & \multirow[t]{2}{*}{$\mathrm{R}^{2}$} & \multirow[t]{2}{*}{$P$} & \multirow[t]{2}{*}{$\mathrm{CV} \%$} \\
\hline & 2,08 & 2,28 & 2,47 & 2,69 & & & \\
\hline Tempo de mastigação total $(\mathrm{min} / \mathrm{dia})^{1}$ & 15,56 & 14,63 & 13,78 & 13,08 & 0,74 & 0,02 & 12,23 \\
\hline Número de bolos ruminais ( $\mathrm{n} \%$ dia $)^{2}$ & 905,74 & 772,17 & 798,55 & 772,94 & - & - & 15,88 \\
\hline Número de mastigações merícicas $\left(\mathrm{n}^{\circ} / \mathrm{dia}\right)^{3}$ & 51720,91 & 50992,09 & 48264,35 & 45628,94 & - & - & 16,84 \\
\hline Mastigações merícicas por bolo $\left(\mathrm{n}^{\circ} / \mathrm{bol}\right)^{4}$ & 59,13 & 66,20 & 62,80 & 58,40 & - & - & 22,05 \\
\hline Tempo de mastigações merícicas por bolo $(\mathrm{seg} / \mathrm{bol})^{5}$ & 40,50 & 40,90 & 41,60 & 38,70 & - & - & 19,71 \\
\hline
\end{tabular}

** = P<0,05; NS = não-significativo; ${ }^{1} \hat{\mathrm{Y}}=23,94-4,06 \mathrm{EM}^{* *} ;{ }^{2} \tilde{\mathrm{Y}}=812,35^{\mathrm{NS}} ;{ }^{3} \tilde{\mathrm{Y}}=49151,57^{\mathrm{NS}} ;{ }^{4} \tilde{\mathrm{Y}}=61,63^{\mathrm{NS}} ;{ }^{5} \tilde{\mathrm{Y}}=40,42^{\mathrm{NS}}$
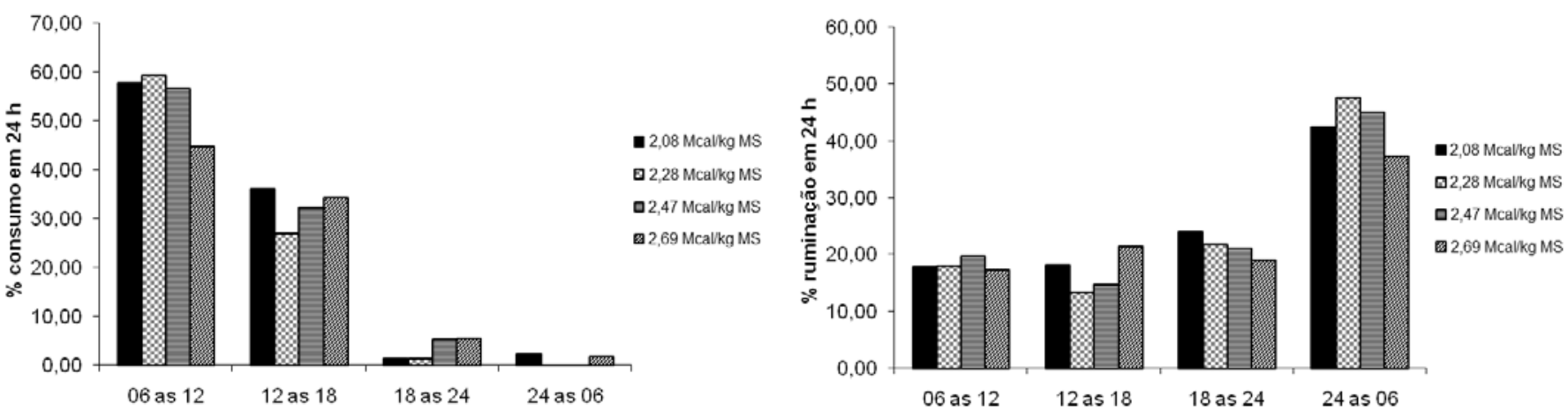

Figura 1 - Distribuição das atividades de consumo e ruminação em quatro períodos de tempo (6 às 12 h; 12 às 18 h; 18 as 24 h; e 24 às 6 h) do dia.

\section{Conclusões}

O aumento dos níveis de energia metabolizável das rações influencia o consumo de nutrientes e comportamento ingestivo de cordeiros da raça Santa Inês na fase de crescimento.

\section{Referências}

ALVES, K.S.; CARVALHO, F.F.R.; VÉRAS, A.S.C. et al. Níveis de energia para ovinos Santa Inês: Desempenho. Revista Brasileira de Zootecnia, v.32, n.6, p.1937-1944, 2003 (supl. 2).

ASSOCIATION OF OFFICIAL ANALYTICAL CHEMISTRY AOAC. Official methods of analysis. 15.ed. Arlington: AOAC International. 1990. 1117p. 
CONRAD, H.R.; PRATT, A.D.; HIBBS, J.W. Regulation of feed intake in dairy cows. 1. Change in importance of physical and physiological factors with increasing digestibility. Journal of Dairy Science, v.47, n.1, p.54-60, 1964.

DADO, R.G.; ALLEN, M.S. Intake limitation, feeding behavior and rumen function of cows challenger with rumen filt from dietary fiber or inert bulk. Journal of Animal Science, v.78, n.1, p.118-133, 1995.

DULPHY, J.P.; REMOND, B.; THERIEZ, M. Ingestive behavior and related activities in ruminants. In: RUCKEBUSH, Y.; THIVEND, P. (Eds.) Digestive physiology and metabolism in ruminants. Lancaster: MTP, 1980. p.103-122.

FRANÇA, S.R.L.; GONZAGA NETO, S.; PIMENTA FILHO, E.C. et al. Comportamento ingestivo de ovelhas Morada Nova no terço final de gestação com níveis de energia metabolizável na dieta. Revista Brasileira de Saúde e Produção Animal, v.10, n.1, p.73-84, 2009.

FORBES, J.M. Voluntary food intake and diet selection in farm animals. Wallington: CAB International, 1995. 532p.

HALL, M.B. Calculation of non-structural carbohydrate content of feeds that contain non-protein nitrogen. Gainesville: University of Florida, 2000. p.25 (Bulletin, 339).

JOHNSON, T.R.; COMBS, D.K. Effects of prepartum diet, inert rumen bulk, and dietary polythylene glicol on dry matter intake of lactating dairy cows. Journal of Dairy Science, v.74, n.3, p.933-944, 1991.

MACEDO, C.A.B.; MIZUBUTI, I.Y.; MOREIRA, F.B. et al. Comportamento ingestivo de ovinos recebendo dietas com diferentes níveis de bagaço de laranja em substituição à silagem de sorgo na ração. Revista Brasileira de Zootecnia, v.36, n.6, p.1910-1916, 2007.

MEDEIROS, G.R.; CARVALHO, F.F.R.; FERREIRA, M.A. et al. Efeito dos níveis de concentrado sobre o desempenho de ovinos Morada Nova em confinamento. Revista Brasileira de Zootecnia, v.36, n.4, p.1162-1171, 2007 (supl.).

MENDES, C.Q.; TURINO, V.F.; SUSIN, I. et al. Comportamento ingestivo de cordeiros e digestibilidade dos nutrientes de dietas contendo alta proporção de concentrado e diferentes fontes de fibra em detergente neutro. Revista Brasileira de Zootecnia, v.39, n.3, p.594-600, 2010.

MENDONÇA, S.S.; CAMPOS, J.M.S.; VALADARES FILHO, S.C. et al. Comportamento ingestivo de vacas leiteiras alimentadas com dietas à base de cana-de-açúcar ou silagem de milho. Revista Brasileira de Zootecnia, v.33, n.3, p.723-728, 2004 .
MERTENS, D.R. Predicting intage and digestibility using mathematical model funtion. Journal of Animal Science, v.64, p.1548-1558, 1987.

MERTENS, D.R. Regulation of forage intake. In: FAHEY JUNIOR, G.C. (Ed.) Forage quality, evaluation and utilization. Madison: American Society of Agronomy, 1994. p.450-493.

MIRANDA, L.F.; QUEIROZ, A.C.; VALADARES FILHO, S.C. et al. Comportamento ingestivo de novilhas leiteiras alimentadas com dietas a base de cana-de-açúcar. Revista Brasileira de Zootecnia, v.29, n.3, p.614-620, 1999.

NATIONAL RESEARCH COUNCIL - NRC. Nutrient requirements of sheep. Washington, D.C., 1985. 99p.

PEREIRA, E.S.; MIZUBUTI, I.Y.; RIBEIRO, E.L.A. et al. Consumo, digestibilidade aparente dos nutrientes e comportamento ingestivo de bovinos da raça Holandesa alimentados com dietas contendo feno de capim-tifton 85 com diversos tamanhos de partícula. Revista Brasileira de Zootecnia, v.38, n.1, p.190-195, 2009.

POLLI, V.A.; RESTLE, J.; SENNA, D.B. et al. Aspectos relativos à ruminação de bovinos e bubalinos em regime de confinamento. Revista Brasileira de Zootecnia, v.25, n.5, p.987-993, 1996.

SNIFFEN, C.J.; O'CONNOR, J.D.; VAN SOEST, P.J. et al. A net carbohydrate and protein system for evaluating cattle diets: II. Carbohydrate and protein availability. Journal of Animal Science, v.70, n.10, p.3562-3577, 1992.

VAN SOEST, J.P.; ROBERTSON, J.B. Systems of analysis for evaluating fibrous feed. In: PIGDEN, W.J.; BALCH, C.C.; GRAHAM, M. (Eds.). Standardization of analytical methodology for feeds. Ottawa: International Development Research Center, 1980. p.49-60.

VAN SOEST, P.J.; ROBERTSON, J.B.; LEWIS, B.A. Symposium: carbohydrate methodology, metabolism, and nutritional implications in dairy cattle. Journal of Dairy Science, v.74, n.10, p.3583-3597, 1991.

VAN SOEST, P.J. Nutritional ecology of the ruminant. 2.ed. Ithaca: Comstock Publishing Associates, 1994. 476p.

UNIVERSIDADE FEDERAL DE VIÇOSA - UFV. Sistema para Análises Estatísticas - SAEG. Versão 9.1. Viçosa, MG, 2007.

WEISS, W.P. Energy prediction equations for ruminant feeds. In: CORNELL NUTRITION CONFERENCE FOR FEED MANUFACTURERS, 61., 1999, Ithaca. Proceedings... Ithaca: Cornell University, 1999. p.176.

WELCH, J.G. Rumination, particle size and passage from the rumen. Journal of Animal Science, v.54, n.4, p.885-895, 1982. 